\title{
European Union policies and their role in combating climate change over the years
}

\author{
Javier Cifuentes-Faura ${ }^{1}$ (D)
}

Received: 3 May 2021 / Accepted: 5 January 2022 / Published online: 8 January 2022

(c) The Author(s), under exclusive licence to Springer Nature B.V. 2022

\begin{abstract}
The worrying environmental situation and increased public awareness in recent years have led many countries to take measures to reduce negative impacts on the environment. The European Union (EU) has been one of the most active in environmental protection with the formulation of policies aimed at preserving the health and well-being of citizens and protecting natural resources. One of the objectives of environmental policies is to make the economy of its member states more environmentally friendly, although this requires finding solutions to major challenges such as climate change, the scarcity of natural resources, the emission of polluting gases, and unsustainable consumption and production. This article reviews the main policies that have been implemented in the EU to reduce environmental problems and the scope of climate change conferences. It offers solutions to promote sustainability that could be adopted by companies, individuals, and governmental institutions to jointly contribute to achieving a more sustainable world, where problems such as climate change or the emission of polluting gases are minimized. The aim is to follow the principles of the Circular Economy and the European Green Deal.
\end{abstract}

Keywords Environmental policies · European Union · Climate change · Circular economy · European Green Deal

\section{Introduction}

The European Union (EU) has one of the highest environmental standards in the world (Selin and VanDeveer 2015). An environmental policy helps the EU economy to become more environmentally friendly, protect Europe's natural resources and preserve the health and well-being of citizens.

EU environmental policies and laws protect the atmosphere and contribute to water sanitation, ensure waste disposal, and help businesses move towards a sustainable economy. While environmental quality is fundamental to the health and well-being of citizens, the EU faces a number of challenges such as climate change, greenhouse gas emissions, and unsustainable consumer production.

To combat climate change, the EU formulates and implements policies and strategies, playing a leading role in international climate negotiations. Conferences such as the 26th United Nations Climate Change Conference of the Parties

Javier Cifuentes-Faura

javier.cifuentes@um.es

1 Faculty of Economics and Business, University of Murcia, Murcia, Spain
(COP26) in Glasgow on 31 October-12 November 2021 demonstrate the involvement and strive for action to combat climate change and help vulnerable nations. The EU is committed to the proper implementation of the Paris Agreement (international treaty on climate change established at COP21). It seeks to promote low-carbon technologies and to protect and improve the quality of the environment.

European environmental policy is based on Articles 11 and 191 to 193 of the Treaty on the Functioning of the European Union, with the fight against climate change being an explicit objective reflected in Article 191 Sustainable development is an overarching objective for the EU, which is committed to preserving, protecting and improving the quality of the environment.

Article 191 of the Treaty on the Functioning of the European Union supports EU participation in United Nations (UN) climate negotiations and defines the EU's environmental objectives, principles, and policies. This article refers to measures at the international level to address environmental problems, in particular, to combat climate change, with cooperation with other countries and international organizations being one of the key objectives of EU environmental policy. 
Climate change is one of today's biggest problems (Kühne 2019; Melidis and Russel 2020). Many countries are developing their own plans to adapt to the expected impacts (Verweij et al. 2006; Huq 2011). In the case of the EU, policies are being put in place to reduce the negative impact on the environment, as it is affecting the health of humans, and essential processes of many organisms, such as growth, reproduction, and survival of early life stages, and may even compromise the viability of some populations. In addition, some ecosystems are at risk of disappearing, and fires and thaws are increasingly frequent.

In view of the growing environmental problems, and the increased awareness of the problem by governmental institutions and citizens, this paper reviews the main policies that have been implemented in the EU to reduce environmental problems, the new policies recently approved and the impact they are having, and proposes solutions to be followed, such as those based on the Circular Economy. In addition, these policies will help to achieve the 17 Sustainable Development Goals that were approved with the 2030 Agenda in 2015, which are a call to action to end poverty, protect the planet, and improve the lives and well-being of citizens (Barbier and Burgess 2017; Fonseca et al. 2020).

The structure of this paper is as follows: epigraph 2 reviews the main milestones in the fight against climate change; epigraph 3 explains what the new "European Green Deal" program consists of, which aims to transform the EU into a modern, resource-efficient, and competitive economy; and epigraph 4, the new European Climate Law. The "The circular economy as a solution to combat climate change" section proposes solutions to combat climate change based on the circular economy and, finally, the "Conclusions" section presents the conclusions.

\section{Main milestones in the fight against climate change}

There have been many developments and advances made in the field of the environment and the fight against climate change at the global level that highlight the growing concern for environmental issues.

- 1949: The United Nations Scientific Conference on the Conservation and Utilization of Resources was the first UN body to address the use and depletion of resources, although its concern was only on how it affected economic and social development.

- 1972: The first United Nations International Conference on the Human Environment is held in Stockholm, known as the First Earth Summit. The UN Environment Program is established in 1973.
- 1979: The First World Climate Conference is held in Geneva.

- 1983: The United Nations Commission on Environment and Development is created.

- 1987: The Montreal Protocol is approved to protect the ozone layer.

- 1988: The Intergovernmental Panel on Climate Change (IPCC) is created.

- 1990: The IPCC publishes the first Assessment Report in Sundsvall, which scientifically confirms evidence of climate change.

- 1992: The Earth Summit is held in Rio de Janeiro, where the United Nations Framework Convention on Climate Change is established. The signatory countries of the Framework Convention commit themselves to adopt measures to mitigate the emissions of gases responsible for global warming.

- 1995: The first Conference of the Parties (COP1) is held in Berlin. The countries present agree to meet once a year to monitor and control global warming and reduce greenhouse gas emissions.

- 1996: COP2 (Geneva) recognizes the need to set legally binding quantitative targets for limiting greenhouse gas emissions by industrialized countries.

- 1997: Binding emission targets (reducing emissions of several greenhouse gases above 1990 levels between 2008 and 2012) were established for rich countries with the adoption of the Kyoto Protocol at COP3.

- 2002: The EU unanimously ratifies the Kyoto Protocol, following its approval by national parliaments. Japan also ratifies the Treaty, as do Canada and New Zealand.

- 2005: The Kyoto Protocol enters into force, without ratification by countries such as the USA, China, and India, despite being the most polluting countries, ratify it, but are not obliged to cut their emissions as they are developing countries.

- 2009: At COP15 (Copenhagen) it is agreed to keep global warming below $2{ }^{\circ} \mathrm{C}$ and the most developed countries commit to long-term financing for developing countries.

- 2010: The Green Climate Fund is created at COP16 (Cancun).

- 2011: A roadmap for a global emissions reduction agreement is established at COP17 (Durhan). Canada announces that it is leaving the Kyoto Protocol.

- 2012: At COP18 (Doha), it is agreed to extend the Kyoto Protocol commitment until December 31, 2020.

- 2015: The Paris Agreement (COP21) is adopted by 195 countries and the EU, with the long-term objective of keeping the global average temperature increase well below $2{ }^{\circ} \mathrm{C}$, aiming to limit the increase to $1.5^{\circ} \mathrm{C}$. The United Nations also publishes the 2030 Agenda of 17 Sustainable Development Goals (SDGs). 
- 2016: The United States and China jointly ratify the Paris Agreement.

- 2017: The United States withdraws from the Paris Agreement and the "One Planet" summit is held, promoted by French President Emmanuel Macron and hosted by the UN and the World Bank to reaffirm the commitment of the member states to the Paris Agreement.

- 2019: The longest climate summit in history (COP25, Madrid) takes place, laying the groundwork for reducing harmful emissions and responding to the climate emergency.

- 2021: At the United Nations climate conference in Glasgow, COP26, nearly 200 countries approved a global agreement to fight climate change, agreeing to take further action to combat climate change and help vulnerable nations. A commitment was made to begin to phase out coal worldwide and limit global warming to $1.5^{\circ} \mathrm{C}$. A number of initiatives were decreed, including:

o Gradually reduce the use of coal worldwide. Countries are asked to update their carbon reduction targets for 2030 .

p Developed countries are urged to double funding for developing countries to help them adapt to climate change.

q It seeks commitments from developed countries to increase financial contributions to reach the target of $\$ 100$ billion per year in funding to help developing countries address climate change.

In many of these developments, the EU has played a major role as one of the main drivers of environmental progress. The EU has always been very active, as demonstrated by the launch of the European Green Deal in 2019 which gave new impetus to climate change policy and action at the EU level and is detailed in the next section.

\section{Importance of the European Green Deal in EU environmental policy}

The European Green Deal is a "new growth strategy that aims to transform the EU into a fair and prosperous society, with a modern, resource-efficient and competitive economy where there are no net emissions of greenhouse gases in 2050 and where economic growth is decoupled from resource use" (European Commission 2019).

In 2019, an initial roadmap is established on the key policies and measures needed to advance the achievement of the European Green Deal which is encompassed within the actions to implement the SDGs. Among the elements of this green plan (Fig. 1) are financing towards the green transition, empowering European industry and small and mediumsized companies, boosting the circular economy, creating a sustainable food system, and preserving biodiversity.

With the European Green Deal, a transformational change was established, with EU Member States committing to making the EU the first climate-neutral zone by 2050 (Claeys et al. 2019; Haines and Scheelbeek 2020; Pianta and Lucchese 2020; Eckert and Kovalevska 2021). The European Commission's vision encompasses almost all EU policies and is in line with the agreement's goal of keeping the global temperature increase below $2{ }^{\circ} \mathrm{C}$ until it is achieved by keeping it at $1.5^{\circ} \mathrm{C}$. To this end, emissions are to be reduced by at least 55\% from 1990 levels by 2030 (Zorpas 2020; Schoenmaker 2021; Brodny and Tutak 2021), which will
Fig. 1 Elements of The European Green Deal. Source: European Commission (2019)

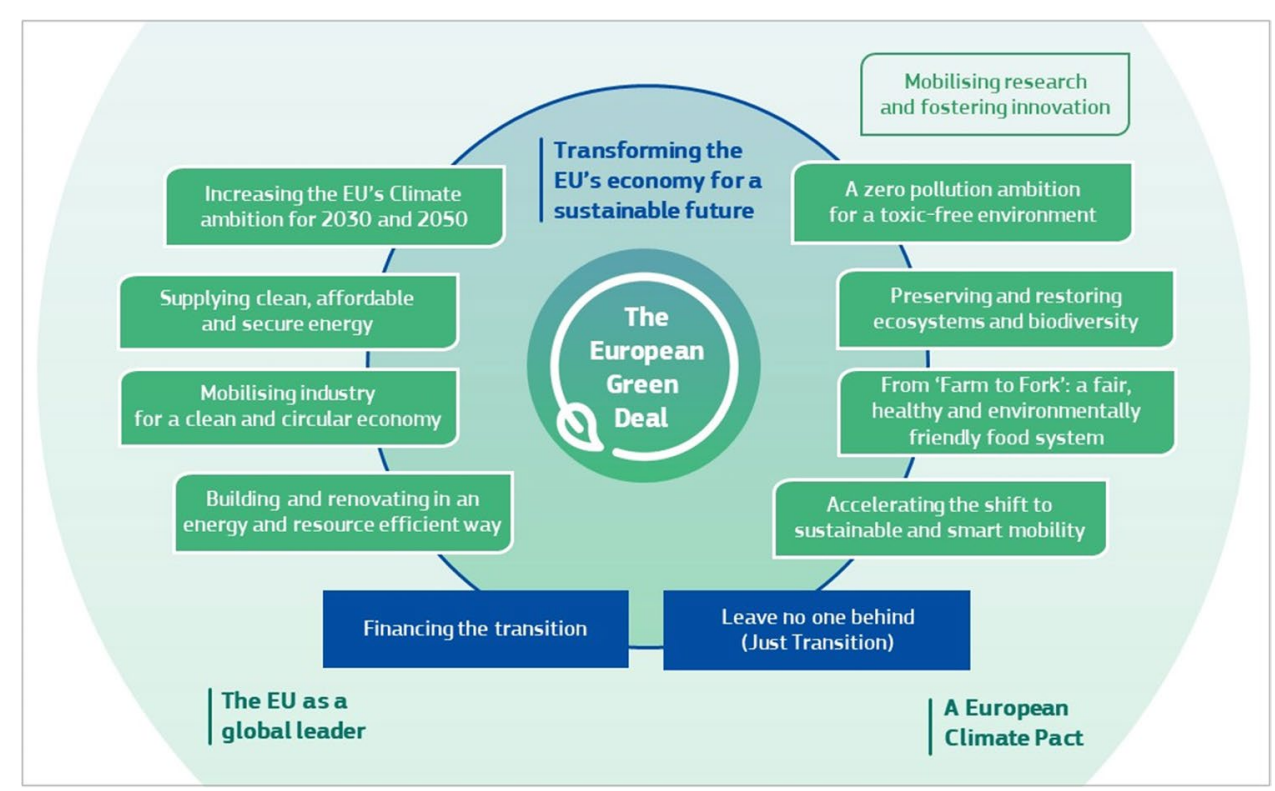


create new opportunities for innovation and for investment and employment.

The transition to greener mobility will enable more accessible, cleaner, and affordable transport (Mock and Díaz 2021; Ovaere and Proost 2021). The European Commission proposes several targets to reduce $\mathrm{CO} 2$ emissions from new passenger cars and vans:

- 55\% lower emissions from passenger cars by 2030 .

- $50 \%$ less emissions from vans by 2030 .

- 0 emissions in new passenger cars by 2035 .

The growth of the market for zero-emission or low-emission vehicles is encouraged, ensuring that citizens have the necessary infrastructure to recharge these vehicles. By 2026, road transport will be subject to emission rights and will put a price on pollution, encourage the use of cleaner fuels and reinvest in clean technologies.

The Commission also proposes carbon pricing for the aviation sector (Chiaramonti et al. 2021), which has so far benefited from an exemption. It also proposes to promote sustainable fuels for aviation. In addition, to decarbonize the economy, the Commission also proposes to extend carbon pricing to the maritime sector (Sedeño López 2021). Targets will be set for large ports to supply shore-side electricity to ships, so as to reduce the use of polluting fuels.

In addition, the green transition offers the European industry a great opportunity to create new markets, as the increased use of renewable energies is expected to generate more employment in these sectors.

The aim to reduce greenhouse gas emissions by at least $55 \%$ by 2030 requires a higher share of renewable energies and increased energy efficiency (Dolge and Blumberga 2021; Kougias et al. 2021). To this end, the Commission intends to increase the binding target for the share of renewable energy sources in the Union's energy mix to $40 \%$.

Reducing consumption is essential to reduce pollutant emissions and energy costs for citizens and businesses. It is therefore proposed to increase energy efficiency targets at the EU level and make them mandatory, in order to achieve an overall reduction of between 36 and 39\% in primary and final energy consumption by 2030 . The taxation system for energy products must also support the ecological transition, so the Commission proposes to harmonize minimum tax rates for heating and transport in line with climate targets, so as to also reduce the social impact and support the most vulnerable citizens. The European Green Deal will improve the well-being and health of all citizens (Rosamond and Dupont 2021) by providing clean water, fresh air, healthy, and affordable food for all budgets, biodiversity, new and energy-efficient buildings, efficient public transport, clean energy, technological innovation, durable products that can be recycled and reused, and future-proof jobs.
The pandemic caused by COVID-19 has slowed economic activity worldwide (Nicola et al. 2020; CifuentesFaura 2020; McKibbin and Fernando 2020) and although there has been a decrease in pollution levels because activity was lower and people stayed at home (Gautam 2020; Wang et al. 2021), it is necessary to maintain low levels of harmful emissions after most activities have been reactivated and returned to normal. Therefore, Europe has launched an ambitious recovery plan based on the European Green Deal (Colli 2020; Rowan and Galanakis; 2020; Becchetti et al. 2021; Hafner and Raimondi 2020; Shoss et al. 2021), this being a lifeline out of the COVID-19 pandemic, as onethird of the $€ 1.8$ trillion investments of the EU Next Generation Recovery Plan will finance the European Green Deal.

Within the European Green Deal, the Commission proposed the first European Climate Act in March 2020 to achieve the goal of climate neutrality by 2050 , which is discussed below.

\section{Progress through the European Climate Law}

The European Climate Law sets the objective of reducing greenhouse gas emissions by at least $55 \%$ by 2030 compared to 1990 levels. It seeks to ensure that all EU policies contribute to achieving the goal of climate neutrality by 2050 and that all sectors of the economy and society play their part adequately (Fleming and Mauger 2021; Levoyannis 2021; Aggestam and Giurca 2021; Sikora 2021).

Among the main objectives of this law are:

- Set the long-term direction for achieving the 2050 climate neutrality target across all policies in a socially just and cost-effective manner.

- Set a more ambitious EU target for 2030 to put Europe on a responsible path to reach climate neutrality by 2050 .

- Create a system to monitor progress and take further action if necessary.

- Provide predictability for investors and other economic actors.

- Ensure that the transition to climate neutrality is irreversible.

EU Member States are obliged to take the necessary measures at the national and EU level to meet the goal of achieving zero net greenhouse gas emissions by 2050, while promoting equity and solidarity between the Member States.

The Climate Act includes measures to monitor progress, such as regular reporting by the European Environment Agency, the governance process of EU Member States' national energy and climate plans, and scientific evidence on climate change and its impacts. Progress will be reviewed every 5 years, in line with the global assessment exercise 
under the Paris Agreement (Oberthür and Dupont 2021; Pouikli 2021).

In July 2021, the Commission adopted a set of proposals to revise all relevant policy instruments to achieve the additional emission reductions by 2030 .

The Climate Act includes not only a legal target for the Union to reach climate neutrality by 2050 , but also the need to enhance the EU carbon sink through a more ambitious regulation (Rietig 2021; Teevan et al. 2021), a process to set a climate target for 2040, a commitment to negative emissions after 2050, and the creation of a European Scientific Advisory Board on Climate Change.

With the climate law, the EU is making progress in achieving the goal of reducing climate change, but other laws and actions, in addition to raising public awareness, will be necessary to put an end to this problem. One of the solutions is to promote a circular economy in all countries.

\section{The circular economy as a solution to combat climate change}

The circular economy is an economic concept that is interrelated with sustainability, and whose objective is that the value of products and materials is maintained in the economy for as long as possible, so that waste generation is minimized (Kirchherr et al. 2017; Morseletto 2020; Cifuentes-Faura 2021).

The European Union created the Action Plan for the Circular Economy (European Commission 2020). These measures consist of making sustainable products the norm in the EU, ensure that products placed on the EU market last longer, are easier to reuse and recycle, empowering consumers, and focus on the most resource-intensive sectors with high potential for circularity, such as electronics and ICT, batteries and vehicles, packaging, plastics, textiles, construction and buildings, food, water, and nutrients. However, sometimes the main barriers to implement a circular economy are cultural, due to lack of consumer interest or awareness and/or low business interest (Korhonen et al. 2018; Kirchherr et al. 2018).

The aim is to generate less waste; make circularity work for people, regions, and cities; and lead global circular economy efforts in the EU. To this end, the European Commission has adopted a number of plans and regulations (European Commission 2021):

- December 2015: European Commission adopted the first circular economy action plan.

- December 2019: European Commission adopted European Green Deal.

- March 2020: European Commission adopted a new circular economy action plan.
- December 2020: European Commission adopted a proposal for a new regulation on sustainable batteries.

- February 2021: Global Alliance on Circular Economy and Resource Efficiency launched.

- October 2021: European Commission adopted the proposal to update rules on persistent organic pollutants in waste.

- November 2021: European Commission adopted the proposal for news rules on waste shipments.

- 2021-2022: Planned adoption date for several initiatives under the action plan.

This adoption plan includes some initiatives that are the basis for protecting the environment and combating climate change. Some of them are listed below.

a) Legislative proposal for substantiating green claims made by companies

This initiative will require companies to substantiate their claims about the environmental footprint of their products or services using standard methods for quantification, so that these are reliable, comparable, and verifiable in all EU member countries, with the aim of reducing the number of companies that give a wrong impression of their environmental impact.

b) Legislative proposal empowering consumers in the green transition

The aim is to help consumers play their part in making the economy more sustainable. The main purpose is to ensure that consumers obtain reliable and useful information about products, to avoid exaggerated environmental information (so-called "greenwashing") and the sale of products whose shelf life has been deliberately shortened. In addition, it seeks to establish minimum requirements for sustainability logos and labels.

iii) EU strategy for sustainable textiles

This strategy will help the EU shift to a climate-neutral circular economy where products are designed to be more durable, reusable, repairable, recyclable, and energy efficient.

It aims to ensure that the textile industry recovers from the COVID-19 crisis in a sustainable way by becoming more competitive and applying circular economy principles to production, consumption, and waste management.

iv) A sustainable products policy initiative including a revision of the Ecodesign Directive

The EU will revise the Ecodesign Directive for more sustainable products. This will lead to more durable, reusable, and recyclable products, which will benefit consumers, the environment, and the climate. 
e) Review of requirements on packaging and packaging waste in the EU

Products should be reused and recycled as much as possible, while packaging waste should be reduced by using recyclable packaging. On the other hand, non-reusable plastic materials should be eliminated or bag fees should be charged, as many supermarkets and clothing stores are already doing to raise consumer awareness.

The EU will review packaging and packaging waste requirements in the EU with the aim of improving packaging design, promoting reuse, and recycling and reducing packaging waste.

\section{f) Update of EU rules on industrial emissions}

It aims to update industry legislation to improve the environment, so as to ensure a clean and healthy environment. In this way, the initiative supports the European Green Deal legislation to achieve zero pollution, as well as EU policies to reduce waste generation and encourage the use of recycled materials.

A just, competitive, and green transition must be ensured, while consolidating the EU's global leadership and commitment in the fight against climate change. The EU is working together with international bodies such as the G7 and G20 to achieve greater economic prosperity and sustainable growth through greater climate ambition.

\section{Conclusions}

Climate change, environmental degradation, or resource depletion are some of the current problems and society in general is becoming increasingly aware of them. In recent years, governmental institutions have made significant progress in improving the environment. This is the case of the European Commission, which plays a key role in the fight against climate change, with the formulation and implementation of various policies and strategies.

There have been several advances over the years, such as the creation of the Intergovernmental Panel on Climate Change in 1988, the Earth Summit held in Rio de Janeiro with the creation of the United Nations Framework Convention on Climate Change in 1992, the Kyoto Protocol in 1997 or the Paris Agreement in 2015 (COP21) to keep the global average temperature increase below $2{ }^{\circ} \mathrm{C}$, trying to limit the increase to $1.5^{\circ} \mathrm{C}$ and the publication of the Agenda 2030 of 17 the Sustainable Development Goals. More recently, the latest conference held in Glasgow (COP26) demonstrates the involvement and struggle to take action to combat climate change and help the most vulnerable nations.
The EU has set more ambitious targets to reduce net emissions by at least $55 \%$ by 2030 compared to 1990 , with the aim of becoming the first climate-neutral continent by 2050, as stated in the first European Climate Act.

It is important that the EU continues to promote these measures, and to this end, the European Commission should create a working group to monitor the proposed objectives and that sanctions are imposed on those countries or organizations that do not comply. It is also very important to educate in sustainability from educational institutions to make future professionals aware of the importance of protecting the environment, so it would be advisable to create a sustainable education plan. Europe could also offer incentives to industries that meet the established targets and do not exceed a certain volume of harmful gases, in order to further promote environmental protection.

The circular economy model should be the basis for EU policies, where sustainable consumption is encouraged and resources used in the EU economy are maintained for as long as possible. The aim should be to maintain the value of products, materials, and resources in the economy for as long as possible and to minimize waste generation.

Solidarity must be a defining principle of the European Green Deal, with collaboration between all Member States and different parts of society. Achieving climate neutrality will require collective efforts and that many citizens, especially young people, change their consumption patterns and have sufficient information to limit their carbon footprint and live in a greener and healthier environment.

With all the laws in place, the EU's natural capital must be protected, conserved, and enhanced; the EU must become a low-emission, resource-efficient, green, and competitive economy; and EU citizens must be protected from environmental risks to health and well-being.

Protecting the environment and encouraging innovation can help create new business and employment opportunities, while enabling new investment. In EU policy, green growth is central to making economic growth environmentally sustainable. It should support a green EU recovery from the pandemic, help spread environmental laws and regulations within and outside the EU, and boost innovation in green products and sustainable technologies of the future.

\section{Availability of data and material Not applicable.}

\section{Declarations}

Ethics approval and consent to participate Not applicable.

Consent for publication Not applicable.

Competing interests The author declares no competing interests. 


\section{References}

Aggestam F, Giurca A (2021) The art of the "green" deal: policy pathways for the EU Forest Strategy. For Policy Econ 128:102456. https://doi.org/10.1016/j.forpol.2021.102456

Barbier, EB., Burgess, JC. (2017). The Sustainable Development Goals and the systems approach to sustainability. Economics:11(1)

Becchetti, L., Piscitelli, P., Distante, A., Miani, A., Uricchio, A. F. (2021). European Green Deal as social vaccine to overcome COVID-19 health \& economic crisis. The Lancet Regional Health-Europe, 2.

Brodny J, Tutak M (2021) The comparative assessment of sustainable energy security in the Visegrad countries. A 10-year perspective. J Clean Prod 317:12842. https://doi.org/10.1016/j. jclepro.2021.128427

Chiaramonti D, Talluri G, Vourliotakis G, Testa L, Prussi M, Scarlat N (2021) Can Lower Carbon Aviation Fuels (LCAF) Really Complement Sustainable Aviation Fuel (SAF) towards EU Aviation Decarbonization? Energies 14:6430. https://doi.org/ $10.3390 / \mathrm{en} 14196430$

Cifuentes-Faura, J. (2020). Crisis del coronavirus: impacto y medidas económicas en Europa y en el mundo. Espaço e Economia. Revista brasileira de geografia econômica, (18). https://doi.org/ 10.4000/espacoeconomia.12874

Cifuentes-Faura, J. (2021). Circular Economy and Sustainability as a Basis for Economic Recovery Post-COVID-19. Circular Economy and Sustainability, 1-7. https://doi.org/10.1007/ s43615-021-00065-6

Claeys, G., Tagliapietra, S., Zachmann, G. (2019). How to make the European Green Deal work. Policy Contribution Bruegel Institute, November 13. Accessed at: https://www.bruegel.org/ 2019/11/how-to-make-the-european-green-deal-work/

Colli, F. (2020). The end of 'business as usual'? COVID-19 and the European Green Deal. European Policy Brief.

Dolge K, Blumberga D (2021) Economic growth in contrast to GHG emission reduction measures in Green Deal context. Ecol Indic 130:108153

Eckert E, Kovalevska O (2021) Sustainability in the European Union: analyzing the Discourse of the European Green Deal. J Risk Financ Manag 14:80. https://doi.org/10.3390/jrfm14020080

European Commission (2019). Communication from the commission to the European Parliament, the European Council, the Council, the European Economic and Social Committee and the Committee of the Regions. The European Green Deal. COM/2019/640 final. Accessed at: https://eur-lex.europa.eu/legal-content/EN/ $\mathrm{TXT} /$ ?qid $=1588580774040 \&$ uri=CELEX\%3A52019DC0640

European Commission (2020). Changing how we produce and consume: New Circular Economy Action Plan shows the way to a climate-neutral, competitive economy of empowered consumers. Accessed at: https://ec.europa.eu/commission/presscorner/ detail/en/ip_20_420

European Commission (2021). Environment. Circular Economy Action Plan. Accessed at: https://ec.europa.eu/environment/ strategy/circular-economy-action-plan_es

Fleming RC, Mauger R (2021) Green and just? An update on the 'European Green Deal.' J Eur Enviro Plan Law 18:164-180. https://doi.org/10.1163/18760104-18010010

Fonseca LM, Domingues JP, Dima AM (2020) Mapping the sustainable development goals relationships. Sustainability 12:3359. https://doi.org/10.3390/su12083359

Gautam S (2020) COVID-19: air pollution remains low as people stay at home. Air Qual Atmos Health 13:853-857. https://doi. org/10.1007/s11869-020-00842-6
Hafner M, Raimondi PP (2020) Priorities and challenges of the EU energy transition: from the European Green Package to the new Green Deal. Russ J Econ 6:374

Haines A, Scheelbeek P (2020) European Green Deal: a major opportunity for health improvement. The Lancet 395:1327-1329. https://doi.org/10.1016/S0140-6736(20)30109-4

Huq S (2011) Lessons of climate change, stories of solutions: Bangladesh: adaptation. Bull At Sci 67:56-59. https://doi.org/10. 1177/2F0096340210393925

Korhonen J, Honkasalo A, Seppälä J (2018) Circular economy: the concept and its limitations. Ecol Econ 143:37-46. https://doi. org/10.1016/j.ecolecon.2017.06.041

Kirchherr J, Piscicelli L, Bour R, Kostense-Smit E, Muller J, Huibrechtse-Truijens A, Hekkert M (2018) Barriers to the circular economy: Evidence from the European Union (EU). Ecol Econ 150:264-272. https://doi.org/10.1016/j.ecolecon.2018.04.028

Kirchherr J, Reike D, Hekkert M (2017) Conceptualizing the circular economy: an analysis of 114 definitions. Resour Conserv Recycl 127:221-232. https://doi.org/10.1016/j.resconrec.2017.09.005

Kougias I, Taylor N, Kakoulaki G, Jäger-Waldau A (2021) The role of photovoltaics for the European Green Deal and the recovery plan. Renew Sust Energ Rev 144:111017. https://doi.org/10. 1016/j.rser.2021.111017

Kühne RW (2019) Climate change: the science behind Greta Thunberg and Fridays for future. OSF Preprints. September 2. https:// doi.org/10.31219/osf.io/2n6kj

Levoyannis, C. (2021). The EU Green Deal and the Impact on the Future of Gas and Gas Infrastructure in the European Union. In Aspects of the Energy Union (pp. 201-224). Palgrave Macmillan, Cham.

McKibbin, W., Fernando, R. (2020). The economic impact of COVID-19. Economics in the Time of COVID-19, 45(10.1162).

Melidis M, Russel D (2020) Environmental policy implementation during the economic crisis: an analysis of European member state 'leader-laggard' dynamics. J Environ Policy Plan 22:198210. https://doi.org/10.1080/1523908X.2020.1719051

Mock P, Díaz S (2021) Pathways to decarbonization: the European passenger car market in the years 2021-2035. Communications 49:847129-848102

Morseletto P (2020) Targets for a circular economy. Resour Conserv Recycl 153:104553. https://doi.org/10.1016/j.resconrec.2019. 104553

Nicola M, Alsafi Z, Sohrabi C, Kerwan A, Al-Jabir A, Iosifidis C, Agha R (2020) The socio-economic implications of the coronavirus pandemic (COVID-19): a review. Int J Surg 78:185-193. https://doi.org/10.1016/2Fj.ijsu.2020.04.018

Oberthür, S., Dupont, C. (2021). The European Union's international climate leadership: towards a grand climate strategy?. J Eur Public Policy 1-20.

Ovaere, M., Proost, S. (2021). Cost-effective reduction of fossil energy use in the European transport sector: an assessment of the Fit for 55 Package. Working Papers of Faculty of Economics and Business Administration, Ghent University, Belgium, $(21 / 1031)$.

Pianta M, Lucchese M (2020) Rethinking the European Green Deal: an industrial policy for a just transition in Europe. Rev Radic Polit Econ 52:633-641. https://doi.org/10.1016/2Fj.ijsu.2020. 04.018

Pouikli, K. (2021). Towards mandatory Green Public Procurement (GPP) requirements under the EU Green Deal: reconsidering the role of public procurement as an environmental policy tool. In ERA Forum (Vol. 21, No. 4, pp. 699-721). Springer Berlin Heidelberg.

Rietig K (2021) Accelerating low carbon transitions via budgetary processes? EU climate governance in times of crisis. J Eur Public Policy 28:1-20. https://doi.org/10.1080/13501763.2021.1918217 
Rosamond J, Dupont C (2021) The European Council, the Council, and the European Green Deal. Politics Gov 9:348-359. https://doi.org/ 10.17645/pag.v9i3.4326

Rowan, N. J., Galanakis, C. M. (2020). Unlocking challenges and opportunities presented by COVID-19 pandemic for cross-cutting disruption in agri-food and green deal innovations: Quo Vadis? Sci Total Environ, 141362https://doi.org/10.1016/j.scitotenv.2020. 141362

Schoenmaker D (2021) Greening monetary policy. Climate Policy 21:581-592. https://doi.org/10.1080/14693062.2020.1868392

Sedeño López, J. F. (2021). Pasado, presente y futuro de la imposición sobre el carbono en España y la Unión Europea. Pasado, presente y futuro de la imposición sobre el carbono en España y la Unión Europea, 167-200.

Selin, H., VanDeveer, S. D. (2015). EU Environmental Policy Making and Implementation: changing processes and mixed outcomes. Paper presented at the 14th Biennial Conference of the European Union Studies Association, Boston, Massachusetts.

Shoss MK, Horan KA, DiStaso M, LeNoble CA, Naranjo A (2021) The conflicting impact of COVID-19's health and economic crises on helping. Group Organ Manag 46:3-37. https://doi.org/10.1177/ 2F1059601120968704
Sikora, A. (2021). European Green Deal-legal and financial challenges of the climate change. In ERA Forum (Vol. 21, No. 4, pp. 681697). Springer Berlin Heidelberg.

Teevan, C., Medinilla, A., Sergejeff, K. (2021). The Green Deal in EU foreign and development policy. ECDPM Briefing Note 131. Maastricht: ECDPM.

Verweij M, Douglas M, Ellis R, Engel C, Hendriks F, Lohmann S, Thompson M (2006) Clumsy solutions for a complex world: the case of climate change. Public Adm 84:817-843

Wang M, Liu F, Zheng M (2021) Air quality improvement from COVID-19 lockdown: evidence from China. Air Qual Atmos Health 14:591-604. https://doi.org/10.1007/s11869-020-00963-y

Zorpas AA (2020) Strategy development in the framework of waste management. Sci Total Environ 716:137088. https://doi.org/10. 1016/j.scitotenv.2020.137088

Publisher's note Springer Nature remains neutral with regard to jurisdictional claims in published maps and institutional affiliations. 